\title{
ALGUNAS \\ CONCEPCIONES \\ SOBRE EL \\ NACIONALISMO \\ ECONÓMICO
}

Jan Patula*

\section{$E_{1}$ nacionalismo constituye una de} las ideologías más poderosas en el siglo XX y uno de los principales factores de cambios políticos, sociales y económicos en el mundo entero, incluyendo a los países de América Latina, África y Asia. Ante quienes lo consideraban como un asunto del pasado, superado en la actualidad por la globalización económica y la transculturación (debido al desarrollo vertiginoso de los medios electrónicos de comunicación), el nacionalismo levanta la cabeza, no para ordenar racionalmente al mundo sino para vengarse con toda crueldad contra los agravios recibidos, reales o imaginarios, y se propone de manera excluyente, pero no menos dominante, regir los destinos de la humanidad. Por doquier presenciamos el renacer de nacionalismos: políticos, económicos, culturales, lingüísticos, etc.

Sin pretender interminables disputas por definir el fenómeno del nacionalismo, ${ }^{1}$ cabe señalar su carácter multifacético, expresado en lecturas diversas, incluso opuestas en muchos casos. "Hay razón para ver en el nacionalismo la imagen de Bella Durmiente o la del monstruo de

* UAM-Iztapalapa.

${ }^{1}$ Ver al respecto K.S. Pinson, Bibliographical Introduction to Nationalism, 1935, Nueva York; K.W. Deutsch, Interdisciplinary Bibliography of Nationalism, 1954, Cambridge, Mass. 


\section{JAN PATULA}

Frankenstein" - constata uno de los estudiosos. ${ }^{2}$ Ello se debe a que el nacionalismo se nutre de diferentes ingredientes. Según las condiciones internas y el entorno externo adquiere distintas formas conforme al contexto en el cual se produce y las metas que persigue.

El nacionalismo se diferencia también a lo largo de la historia; de ahí la paradoja señalada por Minogue: "comienza como Bella Durmiente y acaba como el monstruo de Frankenstein". Ésta característica opera, tanto en el nivel de la misma etnia, como en el transcurso histórico más largo de varias naciones.

En el presente trabajo me propongo dilucidar algunas concepciones sobre el nacionalismo económico; voy a establecer referencias principalmente con los países de Europa centro-oriental, y con øtros países sólo de manera secundaria. Dedicaré una atención especial a la aprehensión global del problema, es decir, a aquellas concepciones que pretenden ofrecer una visión más amplia del fenómeno del nacionalismo económico, tanto en el plano genético (sus orígenes) como en el funcional, más allá de la toma de posición en una determinada cuestión de la política económica del momento. La hipótesis principal sostiene que el nacionalismo económico es ambivalente ideológicamente; se asocia con posiciones de la "izquierda" y la "derecha" (tal como estas posturas se presentaban en el momento); con la plataforma liberal, pero también con la conservadora; con la promoción de la industrialización, así como con la defensa del agrarismo como base del desarrollo económico.

El primer problema por despejar consiste en designar conceptualmente el campo de investigación. Los clásicos del estudio del nacionalismo como H. Kohn, K.W. Deutsch, C.J.H. Hayes, ${ }^{3}$ distinguían principalmente dos formas del mismo: el cultural y el político. En otros trabajos sobre el tema, cuando se menciona el nacionalismo económico ${ }^{4}$ no se llega a

${ }_{3}^{2}$ K.R. Minogue, Nacionalismo, 1968, Buenos Aires, p. 241.

${ }^{3}$ Cf. Los trabajos: C.J.H. Hayes, Essays on Nationalism, 1926, Nucva York; así como Nationalism: A Religion, 1960, Nueva York; H. Kohn, The Idea of Nationalism. A Study of Its Origins and Background, 1967, Nueva York, 8a. ed.; K.W. Deutsch, Nationalism and Social Communication. An Inquiry into the Foundations of Nationality, 1967, Cambridge, 2a. ed.

${ }^{4}$ Así lo hacen muy a menudo los economistas o los politólogos, cf. A.D. Smith, Nationalism in the Twentieth Century, 1979, Oxford, p. 9-15. 


\section{CONCEPCIONES DE NACIONALISMO ECONÓMICO}

precisar su lugar en la estructura, se le concibe más bien como el instrumento para lograr las metas del nacionalismo político o su prolongación. ${ }^{5}$ En la mayoría de los casos, resulta implícito que el segundo es la forma más elevada y completa del nacionalismo.

Esta dificultad de precisar el campo propio del nacionalismo económico se origina porque no son claros sus componentes; éstos se cruzan y mezclan con otros. De ahí la polivalencia de'sus contenidos y el resultante carácter amorfo, ya que en sus incorporaciones político-económicas contiene, al lado de rasgos comunes, atributos muy particulares. No es fácil, tampoco, distinguir sus formas y enumerar instrumentos de los cuales se sirve en nombre del nacionalismo económico, Tomemos como ejemplo, en el tema del proteccionismo, el interrogante que cuestiona si cada manifestación del proteccionismo corresponde al nacionalismo económico.

¿Es acaso el proteccionismo industrial, en su primera fase, de Alemania en la época de Friedrich Lis? ¿El de Francia en el período napoleónico? ¿El de Europa suroriental a finales del siglo XIX, y de los países en vías de desarrollo en nuestros tiempos? ${ }^{6}$ De la misma manera, cabe preguntarse si por nacionalismo económico debemos considerar cualquier anhelo de autosuficiencia que se manifiesta, como por ejemplo limitar el flujo de capitales extranjeros y de mano de obra proveniente de otros países.

Por otra parte, no deja de ser importante la procedencia del investigador y la coyuntura económica en donde se estudia el fenómeno del nacionalismo económico. A grosso modo, podemos constatar que los investigadores cuyo origen data de países altamente desarrollados, con estatus de potencias económicas y estables políticamente desde mucho tiempo, tienden a despreciar al nacionalismo económico, a criticar sus resortes y metas y, en términos generales, demuestran poca comprensión hacia diversas manifestaciones de éste. Y vice versa, los estudiosos procedentes de países con tendencia dinámica suelen demostrar su plena

${ }^{5}$ L.L. Lorwin, Economic Nationalism and World Co-operation, 1945, Nueva York, Londres, p. 218 ss.

${ }^{6}$ Así parecen afirmar I.T. Berend, G. Ránki, The Role of the State, en: I.T. Berend, G. Ránki (eds.), The European Periphery and Industrialization, 17801914, 1982, Budapest, p. 71-2. 


\section{JAN PATULA}

simpatía, si no identificación, con las prácticas del nacionalismo económico y le otorgan el signo positivo; incluso, excavan profundamente en los resortes históricos para apoyar una política económica netamente nacionalista. ${ }^{7}$

Del mismo modo, en una coyuntura económica de depresión y crisis prevalecen tendencias que enfatizan la necesidad de emprender virajes nacionalistas, de franca oposición hacia el capital extranjero y las inversiones foráneas, así como de defensa de prácticas autárquicas. Ilustrativo al respecto puede ser la gran crisis de 1929, y recientemente -con respecto a México- la "stagflación" de 1995; la combinación del estancamiento, si no profunda depresión económica, con la inflación desbordante. ${ }^{8}$ No sería difícil encontrar ejemplos de este tipo en otros países en ocasiones de crisis económicas.

En el período de entreguerras mereció una gran popularidad $\mathrm{M}$. Manoilescu, profesor de la Escuela Politécnica en Bucarest, y alto funcionario del gobierno rumano. En 1929 expuso sus tesis en el libro: Teoría de protección y el comercio internacional que se tradujo al inglés, francés, italiano, portugués y, en una versión corregida, al alemán. El punto de partida de sus reflexiones sobre el nacionalismo económico se ubica en una afirmación que sustenta para los países agrícolas, como lo fueron Rumania y otros Estados centroeuropeos de entonces: mantener

32 la estructura económica existente equivale a conservar su estatus de clientes de los países altamente desarrollados. ${ }^{9}$

Su concepción del nacionalismo económico se origina en promover y desarrollar la industrialización del país. Su idea motriz se basa en cómo lograr los fundamentos de la autonomía económica y lo indispensable que es impulsar la industrialización, así como el "derecho natural" de cada pueblo y Estado. Sólo ella permite romper el círculo vicioso de la

${ }^{7}$ Su origen se remonta a las tesis del economista argentino R. Prebisch (1955). Esta concepción la desarrollaron posteriormente C. Furtado, F.H. Cardoso, T. Dos Santos, A.G. Frank, S. Amin, A. Emmanuel y I. Wallerstein.

${ }^{8}$ Cf. La política de New Deal en: P.K. Conkin, The New Deal, 1969, Nueva York; y la política nazi en cuestiones económicas en: F.L. Neuman Behemonth, The Structure and Practice of National Socialism, 1944, Nueva York, 2a. ed.

${ }^{9}$ M. Manoilescu, The Theory of Protection and International Trade, 1931, Londres, p. 208. 


\section{CONCEPCIONES DE NACIONALISMO ECONÓMICO}

dependencia y la petrificación del atraso. Manoilescu defiende el uso del proteccionismo para la naciente industria en la fase inicial del proceso, por considerar que no puede resistir la competencia con los países altamente desarrollados. Tal orientación económica no está en oposición con los intereses a largo plazo de estos últimos, ya que los países atrasados que inicien su industrialización se convertirán bien pronto en compradores de bienes de los países altamente avanzados.

De este modo, se ampliará el mercado mundial con beneficio más generalizado. El desarrollo económico de las naciones atrasadas se producirá a partir del ingreso de éstas en la circulación de producción a escala mundial. ${ }^{10}$ Sólo después de lograr un cierto nivel de industrialización es recomendable abrirse a la competencia internacional, la cual podría convertirse en la palanca del progreso.

El trabajo de Manoilescu disiente de los cánones de la economía política neoclásica y de la inspiración liberal. El economista y político rumano estaba muy consciente de la crisis de los valores liberales y de la incapacidad de los gobiernos partidarios del liberalismo económico de responder a los desafíos del desempleo y la depresión en los países desarrollados y de la postración generalizada en los atrasados. ${ }^{11}$ Abiertamente rechaza el dogma liberal en cuanto a que la utilidad deba ser el principal móvil de la actividad económica: "esto sería el peor error. La ganancia capitalista es una cuestión muy superficial; el beneficio del Estado y la nación es lo decisivo". 12 Por ende, el autor admite promover la producción que no se rige según el principio de la ganancia y por lo mismo aporta pérdidas; en consecuencia, sólo puede ser llevada a cabo por el Estado que la considere útil para el país por otras razones.

Las tesis de Manoilescu, con respecto a romper el círculo vicioso del atraso mediante una política proteccionista de industrialización, pecan por su visión parcial. Ya en los años 30, M. Kalecki, un economista polaco que adquirió prestigio por sus estudios de los países en vías de desarrollo, señaló: "Es ciertamente erróneo considerar, como lo hace Manoilescu,

${ }^{10}$ Ibidem, p. 94-105.

${ }^{11}$ Cf. Sus otros trabajos, Siècle du corporativisme, 1936, París; Die einzige Partei, 1941, Berlín.

${ }^{12}$ M. Manoilescu, The Theory.., op. cit., p. 19. 


\section{JAN PATULA}

al proteccionismo como la solución universal de la cuestión de la industrialización de los países agrícolas". 13

El economista polaco remarcó que para los países atrasados, en su camino del crecimiento, se levantan múltiples obstáculos que residen principalmente en su estructura social. Muchos otros estudios históricos sobre el atraso económico en los países de Europa central mostraron en relieve, precisamente, las barreras de las estructuras sociales y de las mentalidades colectivas profundamente arraigadas. ${ }^{14}$

Por su parte J. Viner, economista inglés, reconociendo la importancia crucial de encontrar soluciones al problema del desarrollo para los países atrasados, rechazó los postulados de Manoilescu: "La tarea de encontrar una defensa intelectualmente satisfactoria para el proteccionismo económico sigue siendo muy actual y esta vez el intento de Manoilescu resultó ser fallido". $15 \mathrm{El}$ autor rumano, por su parte, siguió defendiendo sus tesis, desarrollando argumentos en su favor hasta los tiempos de la segunda guerra mundial. 16

Las ideas de Manoilescu encontraron una amplia difusión no sólo en su natal Rumania, donde se erigieron en el fundamento de la política económica en los años $30,{ }^{17}$ sino también en Polonia, donde un influyente grupo de periodistas y hombres de negocios llamado Leviatan, se encargó de su propagación. ${ }^{18}$ También en Brasil, los círculos del gran

34 capital nacional evocaban las tesis del autor para defender altos aranceles en contra de las exigencias de bajarlos de sus opositores, quienes

${ }^{13}$ M. Kalecki; Obras, vol. 5, 1985, Varsovia, p. 291 (en polaco).

${ }^{14}$ Cf. W. Kula, Atraso, crecimiento y desarrollo, 1962, Varsovia (en polaco); A. Janos, Modernization and Decay in Historical Perspective, 1978, Berkeley; F. Hertz, The Economic Problems of Danubian States, 1947, Londres; N. Spulber, The State and Economic Development in Eastern Europe, 1966, Nueva York.

${ }^{15}$ J. Viner, reseña del libro en Journal of Political Economy, 1932, t. XL, $n^{\circ} 1$, p. 143.

${ }^{16}$ M. Manoilescu, "Die Theoretische Problematik des Aussenhandels. Synthese-Beweisführung-Polemik" en, Weltwirtschafliches Archiv, 1940, n ${ }^{\circ}$ 1, p. 1-78.

${ }^{17}$ D. Chirot, Neoliberal and Social Democratic Theories of Development, 1978, Berkeley, p. 31-52.

${ }^{18} \mathrm{~J}$. Kofman, Leviatan y las cuestiones fundamentales económico-politicas en la Segunda República. De la historia de los círculos del gran capital en Polonia, 1986, Varsovia, p. 24-47 (en polaco). 


\section{CONCEPCIONES DE NACIONALISMO ECONÓMICO}

creían que la apertura más amplia posible traería al país mayores beneficios. ${ }^{19}$ Como se puede observar, los ecos de esta discusión perduran hoy en día, aunque el autor de estas concepciones fue olvidado en el ambiente de los economistas profesionales.

Es interesante recordar que las concepciones del nacionalismo económico se incrustaron también en el pensamiento de los economistas liberales en los años 30 , es decir, en el período de la gran crisis. T.E. Gregory, economista inglés de gran renombre entonces, abordó el problema del nacionalismo económico en el contexto más vasto de corrientes ideológicas y políticas de la época. El autor entendió la esencia del problema en: "concepciones que postulan el incremento del poder del Estado como decisivo para dirigir los asuntos económicos".20 Según Gregory, los partidarios de este punto de vista, en caso de un conflicto "entre el bienestar del individuo y el poder del Estado van a elegir siempre y de manera consciente (...) como cuestión de un cálculo racional, como la meta final que guía, el poder del Estado en lugar del bienestar individual". "La ideología del nacionalismo - precisa - supedita siempre los intereses económicos al prestigio de la fuerza nacional y colocá su nación por encima de las otras".

Gregory percibe como condición para el surgimiento del nacionalismo económico la aparición de ideas nacionalistas de sustrate racial, característico en su época y, según su punto de vista, en Europa centro-oriental y Asia. ${ }^{22}$ Independientemente de que los ejemplos manejados por él son más complejos, no es cierta su tesis que propone que los dos objetivos (el bienestar individual y el poder del Estado) son, para los partidarios del nacionalismo económico, excluyentes. Con excepción de los ideólogos fascistas, quienes bajo el espíritu del totalitarismo identificaban el Estado con la nación, los propagadores del nacionalismo económico concebían el carácter complementario entre la acción del Estado y el bienestar de los individuos y la sociedad. Para ellos, la política

19 J.D. Wirth, The Politics of Brazilian Development, 1930-1954, 1970, Stanford, Cal., p. 47.

${ }^{20}$ T.E. Gregory, "Economic Nationalism" en, International Affairs, 1931, t. X, $\mathrm{n}^{\circ} 3$, p. 289 ss.

${ }_{21}^{21}$ ibidem, p. 290.

22 Ibidem, p. 297. 


\section{JAN PATULA}

tendiente a reforzar el Estado produce también el reforzamiento de los individuos.

Tampoco resulta acertada la aseveración del autor que señala: para obtener "la dominación política es indispensable lograr la situación en que la minoría étnica sea débil económicamente". Múltiples casos, por ejemplo el de los judíos en Europa centro-oriental en el siglo XIX y hasta la segunda guerra mundial; de los chinos en toda Asia suroriental; y los hindúes en África del sur en los dos últimos siglos, contradicen la aseveración de Gregory. ${ }^{23}$

Estas lagunas interpretativas del nacionalismo económico en Gregory hay que atribuirlas a su concepción del nacionalismo integrista; es decir, unifica todos los aspectos del problema al ascenso ideológico y político del nazismo en Alemania, con su racismo visceral y el odio aberrante hacia los judíos. ${ }^{24}$ Por consiguiente, Gregory consideraba al nacionalismo económico de manera uniforme, sin distinguir si se trata de su expansión hacia afuera o se dirije más bien hacia adentro de cada país.

Atinada, en cambio, hay que estimar la apreciación de Gregory acerca de que el nacionalismo económico surja en el clima de la amenaza de la guerra, ${ }^{25}$ tal como se evidenció un par de años después. Aunque el autor no se dedicó a investigar el trasfondo socio-económico de la ideología y práctica del nacionalismo económico, llamó la atención sobre los condicionantes étnicos (según él, raciales), del surgimiento de este fenómeno.

Escrito desde la posición de los países anglosajones, desarrollados en todo sentido, el libro no captó los elementos racionales y positivos del nacionalismo económico en los países atrasados. No sorprende, pues, su actitud negativa, de crítica, hacia este asunto. No se debe pasar por alto

${ }^{23}$ Ibidem, p. 290.

${ }^{24}$ Cf., por ejemplo, Hitler atribuía a los judíos tanto la autoría de la revolución bolchevique en Rusia y del comunismo a escala mundial, como los acusaba de dominar económica y financieramente en los principales países occidentales, con los Estados Unidos a la cabeza, véase A. Hitler, Mi lucha, 1971, México, p. 181-92.

${ }^{25}$ Esta tesis la compartieron varios autores de la época; cf. F. Hertz, The Economic Problems of Danubian States: A Study in Economic Nationalism, 1947, Londres; L. Robbins, The Economic Problems in Peace and War, 1947, Londres; E.H. Carr, Nationalism..., op. cit. 


\section{CONCEPCIONES DE NACIONALISMO ECONÓMICO}

que el autor formuló sus tesis bajo la presión de los movimientos nacionalistas y abiertamente fascistas en muchos países del Viejo Continente. En este sentido demostró una profunda perspicacia, de aquí se deriva su gran mérito. Por otro lado, la globalización de la economía que él quiso promover se encontraba en pañales. De todas maneras, sus ideas sobre el tema las retomó, 30 años después A. Breton en el artículo: "The Economics of Nationalism". 26

Desde las posiciones socializantes inspiradas en cierta medida en el marxismo, huelga detenerse un momento en las ideas sobre el nacionalismo económico en el período de entreguerras que presentó $\mathrm{O}$. Lange en 1927. En un breve escrito: "El nacionalismo económico" definió su esencia como: "una política aduanera proteccionista e incluso prohibicionista". ${ }^{27}$ Su ideología y la práctica correspondiente las calificó de anacrónicas y reaccionarias porque inhibían el proceso de formación de un solo sistema de economía mundial y contribuían a levantar barreras entre las economías nacionales. Según el autor de la Economía política del socialismo, particularmente en los países atrasados económicamente, los principales promotores del nacionalismo económico están representados por esta fracción de la burguesía que había perdido la independencia económica en favor de la progresiva concentración monopolista. En contra de esta ideología se levanta aquella burguesía relacionada "con grandes monopolios capitalistas con carácter internacional".28

A la luz del análisis circunstancial de la época y también del desarrollo ulterior del fenómeno, la concepción de Lange sobre el nacionalismo económico no resistió la prueba del tiempo; al limitar su alcance únicamente a la esfera de la política aduanera, redujo su contenido y equiparó el nacionalismo económico con la autarquía. No distinguió entre el nacionalismo económico de los pequeños Estados y el de las grandes potenciás. Definitivamente, las ideas de Lange corresponden a su fase juvenil de pensamiento; a la confianza en el mecanismo ricardiano de igualar las desproporciones del desarrollo, al menos a escala europea. En su fase madura, Lange ya no retomó estos planteamientos y, por

${ }^{26}$ Publicado en Journal of Political Economy, t. LXXII, 1967, $\mathrm{n}^{\circ} 4$.

${ }^{27}$ O. Lange, Obras, 1973, Varsovia, t. 1, p. 26-8 (en polaco).

${ }^{28}$ Ibidem, p. 36-8. 


\section{JAN PATULA}

ejemplo, con respecto al desarrollo por seguir después de la segunda guerra mundial en su natal Polonia, postuló las tesis del crecimiento autónomo de la base industrial en la primera fase del socialismo. ${ }^{29}$

En el contexto de la gran crisis económica de los años 30, huelga mencionar el pequeño texto de 1934, de G.D.H. Cole, destacado militante del partido laborista británico y connotado economista e historiador. Observó que el proteccionismo aduanal generalizado y el desarrollo de exportaciones de tipo dumping, consideradas como prioritarias dentro de las políticas económicas de los principales países industrializados, producen efectos muy negativos ya que eliminan la competencia internacional y contribuyen al aumento de precios y al encarecimiento de la producción. Además, las exportaciones dumping provocan el alza de los precios en el mercado interno de cada país y, con ello, la baja del nivel de vida de la población, porque al excluir la división internacional del trabajo tienden a aumentar los precios en el mercado interior para compensar las pérdidas sufridas en el mercado externo. Todo ello perturba y repercute en el funcionamiento de la economía, tanto a escala nacional, como internacional. ${ }^{30}$

La argumentación del autor se inscribe dentro de la economía neoclásica, aunque el mismo Cole evoca a menudo a Keynes y no resulta del todo convincente, al menos para los países anglosajones. En cambio, para

38 los Estados fascistas como Italia y Alemania se pudo notar el carácter dumping en sus exportaciones debido principalmente al fuerte desempleo, que incluso se trató de aminorar por todos los medios; entre otros, brindando el impulso a la industria del armamentismo. ${ }^{31}$ En todo caso, se debe enfatizar la condena de la ideología y la praxis del nacionalismo económico en el trabajo de Cole, que logró una gran resonancia en sus tiempos.

En cuanto a los años de la segunda guerra mundial es menester citar el trabajo International Economic Desintegration, de W. Röpke, economista alemán exiliado en Inglaterra durante el régimen de Hitler y uno de los más influyentes teóricos de la futura "economía social del merca-

\footnotetext{
${ }^{29}$ O. Lange, Obras, 1976, Varsovia, t. 3, p. $49-54$ (en polaco).

${ }^{30}$ G.D.H. Cole, Studies in World Economies, 1934, Londres, p. 15.

${ }^{31}$ Sobre la política de los países fascistas, véase S.I. Woolf (ed.), La naturaleza del fascismo, 1976, México, p. 87-93.
} 


\section{CONCEPCIONES DE NACIONALISMO ECONÓMICO}

do”, puesta en marcha en la República Federal de Alemania después de la segunda guerra mundial. Se destaca por una visión amplia del nacionalismo económico, al incluir en su análisis los factores extraeconómicos, tanto objetivos como subjetivos, así como una percepción histórica del problema. El nacionalismo económico - juzga el autor-es un fenómeno mutante en el transcurso del tiempo y en los espacios geográfico-políticos donde opera. Al nacionalismo tipo "total" hay que diferenciarlo de las prácticas proteccionistas que se iniciaron en Europa en el siglo XVIII, en los albores de la industrialización. "Los viejos argumentos y los motivos del nuevo nacionalismo económico siguen siendo vigentes como siempre, pero mucho más importante que ellos llega a ser la idea que sin importar sus ventajas y desventajas se presenta ahora como algo indispensable para la política de regular todo el proceso económico con el fin de obtener la estabilidad económica mediante soluciones dentro de la economía nacional independientemente del resto del mundo". 32

Röpke, al igual que K. Polanyi, ${ }^{33}$ analizaba los años 30 como síntoma de una profunda crisis, la cual califica de "histórica"; algo parecido había ocurrido en 1300-1500 con respecto al sistema económico medieval o en los siglos III-V, al referirse al Imperio Romano. El inicio de la crisis contemporánea la ubica de manera simbólica en julio de 1914, es decir, en la coyuntura de agudización de tensiones político-económicas y nacionales que desembocaron en el estallido de la primera guerra mundial. ${ }^{34}$

El futuro inspirador de la economía social del mercado no duda en condenar este nuevo viraje de los años 30 por considerarlo una "enfermedad" y una "descomposición del sistema económico mundial". Röpke advierte del peligro que confronta el nacionalismo económico de los años 30 , porque puede conducir al "colectivismo económico", a un "totalitarismo político e incluso cultural" y en relaciones internacionales hacia "el incremento del peso de grandes unidades (estatales-J.P.) sobre más

${ }^{32}$ W. Röpke, International Economic Desintegration, 1942, Londres, p. 83-109.

${ }^{33}$ Cf. su libro, La gran transformación, 1975, México, p. 43-58.

${ }^{34}$ Es interesante anotar que mucho más tarde, en 1955, R. Aron, el gran filósofo y sociólogo francés, denominó el siglo XX, iniciándose - según él - en 1914, como "centuria de la guerra total". Véase su libro bajo el mismo título; existe la traducción al español. 


\section{JAN PATULA}

pequeñas". ${ }^{35}$ En concreto, el autor vislumbraba tal tendencia en Alemania y la comparaba con los países de Europa centro-oriental.

Röpke estaba convencido de que el nacionalismo económico es dañino; sea el agrícola de los países desarrollados, sea el monetario (manipulación con tasas de cambio), sea que se exprese en la concepción del "pleno empleo", 36 así como en las prácticas autárquicas, por considerarlas desperdiciadoras desde el punto de vista de los costos de producción. A su vez, se justifican las prácticas del nacionalismo económico para emprender la industrialización de los países atrasados, ya que los beneficios sobrepasan los daños en la fase inicial del proceso.

El autor no se limitó a analizar únicamente el fenómeno del nacionalismo económico del pasado y su presente, sino que esbozó vías de su superación a escala global, tomando en cuenta los intereses tanto de los países desarrollados como de los atrasados. Así, recomendó que los países industrializados deben de renunciar al excesivo proteccionismo de su agricultura en favor de la llamada "tercera vía", alternativa entre el anhelo a la autosuficiencia agrícola y la falta total de ésta. En concreto, postuló que los países industrializados deberían concentrarse en su política agrícola y apoyar aquellas ramas de su agricultura que requieren grandes inversiones del capital, dejando la producción restante a los países atrasados que disponen de exceso de mano de obra. De esta manera, se lograría una mayor cooperación y división internacional del trabajo. $^{37}$

Del mismo modo, se debería complementar el "nacionalismo industrial" de los países agrícolas, tradicionalmente atrasados, con el desarrollo de las relaciones internacionales comerciales, incluyendo -en primer lugar-los intereses de los países industrializados. Lo anterior se lograría debido a que los primeros se convertirían en importadores de medios de producción procedentes de los segundos.

Röpke otorgaba a la industrialización una dimensión cuasi historiosófica, al considerarla como: "el camino más apropiado mediante el cual un país dado se está incorporando a la esfera de la civilización occidental

35

W. Röpke, op. cit., p. 208.

${ }^{36}$ Aquí se critica de manera velada a la teoría de Keynes, con respecto a promover el empleo como medio de la reactivación económica.

${ }^{37}$ W. Röpke, op. cit., p. 162 y ss. 


\section{CONCEPCIONES DE NACIONALISMO ECONÓMICO}

y el capitalismo". 38 En consecuencia, la industrialización de los países atrasados, lejos de representar una amenaza competitiva para los industrializados, sirve a la reconstrucción y a una renovada integración económica a escala mundial. Con ello, el economista alemán demostró una visión global de la situación y una proyección hacia el futuro que, desafortunadamente, no se llevó a cabo hasta nuestros días.

Al hablar de las concepciones sobre el nacionalismo económico en el período de la posguerra, se debe recordar el trabajo publicado en 1945 por E.H. Carr, connotado historiador y laborista de izquierda, intitulado: Nationalism and After. El autor de la monumental obra sobre la historia de la revolución soviética obtuvo prestigio intelectual en cuanto al estudio del fenómeno del nacionalismo, por haber dirigido una investigación colectiva sobre el tema bajo auspicios de Royal Institute of International Affairs; éste se publicó en 1939 bajo el título: Nationalism. En el pequeño libro de 1945, Carr se abocó a buscar las raíces del fenómeno y se concentró en el incremento del papel del Estado en la conducción económica desde el último tercio del siglo XIX.

Dicho autor distinguió tres etapas del nacionalismo económico y ubicó la tercera en los años 1914-1939. En ella, la política estatal se caracterizó por el énfasis en la esfera social, que se tradujo en defender el nivel de salarios y en luchar contra el desempleo; por haber establecido esta prioridad se dirigió contra la política nacional de otros gobiernos. Al juzgar negativamente al nacionalismo, incluyendo al nacionalismo económico, el cual se extendió por todo el mundo, sin excluir a la Unión Soviética, Carr pareció entender parcialmente las razones de los países subdesarrollados que pretendían romper la barrera del atraso económico, aunque juzgó estas aspiraciones, egoístas. ${ }^{39}$

Otro gran especialista sobre cuestiones del nacionalismo económico fue M. Heilperin, de origen polaco, quien en la posguerra se estableció en el Occidente. Ya en su primera gran obra: Trade of Nations se refería metafóricamente, mediante este título, al famoso tratado de A. Smith, padre del liberalismo económico; en él señaló algunos motivos del nacionalismo económico que posteriormente (1960) desarrolló en Studies in Economic Nationalism. El eje central de su concepción constituye

${ }^{38}$ Ibidem, p. 165 y ss.

${ }^{39}$ E.H. Carr, Nationalism and After, 1945, Londres, p. 189-93. 


\section{JAN PATULA}

la oposición entre el llamado sistema colectivista y el de la libre empresa. Cabe precisar que Heilperin califica de ideologías y prácticas colectivistas a todas aquellas que enfatizan el elemento colectivo sobre el individual, como el comunismo, el socialismo, el fascismo; en cambio, los términos "libre competencia", "liberalismo", sustituyen en múltiples contextos al término "capitalismo". 40

El nacionalismo económico en su versión radical, nacido de la gran depresión, se caracteriza, entre otros, por los siguientes rasgos: el control estatal de la tasa de cambio como instrumento para obtener el balance de pagos positivo, y esta meta se eleva al nivel de raison d'état; el impulso al pleno empleo mediante el apoyo a las exportaciones y la limitación de importaciones; el forzar las relaciones comérciales bilaterales en detrimento de las multilaterales. ${ }^{41}$ Para el autor resulta obvio que todas estas prácticas y sus justificaciones teóricas representan la negación del orden liberal y constituyen una amenaza para el comercio internacional.

Entre una concepción estrecha y una amplia del nacionalismo económico, Heilperin elige la segunda como más apropiada para designar el fenómeno contemporáneo. La concepción estrecha "pone el signo de igualdad entre el nacionalismo económico y la política gubernamental tendiente a la autosuficiencia en todos los planos, pero excluye de su campo la política (es decir, el proteccionismo, J.P.) que interviene en las

42 relaciones económicas internacionales sin llegar a la separación de un país dado, del resto del mundo". 42 El autor considera que la definición amplia corresponde mejor a las prácticas colectivistas en boga en los últimos tiempos. Las fuentes del nacionalismo económico las encuentra en el mercantilismo de los siglos XVII-XVIII y en la concepción de Fichte acerca del Estado comercial cerrado; los impulsos contemporáneos provienen de la creciente injerencia estatal, especialmente en la planificación, asociada cstrechamente con la idea de la autarquía cconómica. Este nuevo viraje lo observa en la práctica llevada a cabo en Alemania por H. Schacht, ministro de cconomía en el gobierno de Hitler, y en los países democráticos, propagado con cierto éxito por J.M. Keynes. Particularmente, la concepción del pleno empleo de este último - cn

${ }^{4}$ Ibidem, p. 18-20. 


\section{CONCEPCIONES DE NACIONALISMO ECONÓMICO}

opinión de Heilperin - promueve el reforzamiento del nuevo nacionalismo económico. 43

Sobre el nacionalismo económico en los llamados países del Tercer Mundo, dedicó bastante atención H. Johnson, economista contemporáneo de gran renombre, quien dirigió un seminario especializado en esta materia, Con base en los trabajos de G.S.. Becker y A. Downs (ambos publicados en 1957) y de A. Breton (1964), emprendió un estudio global sobre el problema. Según él, la política del nacionalismo económico hace hincapié sobre la industrialización y el desarrollo de las ramas y sectores de la producción que se consideran como símbolos de "identidad nacional" en los países en vía de desarrollo y, al mismo tiempo, sirven para incrementar la cohesión nacional del Estado (por ejemplo, las obras de infraestructura, los medios de transporte, etc.) La meta final de esta política consiste en crear, y posteriormente reforzar, la clase media y/o grupos de personas de educación superior, con el fin de asegurar puestos de prestigio bien remunerados.

Tales metas se lograrán gracias a la ampliación de la propiedad estatal, campo propicio para los puestos de realce bien recompensados, y a la modernización de la administración estatal. Aquí se combinan los factores económicos con los extraecónómicos de satisfacción psicológica (participación en el alto nivel del poder). A estos últimos el autor, siguiendo a A. Breton, los califica de "ingresos psicológicos" porque se refieren a la satisfacción por el desarrollo nacional del país. ${ }^{44}$ Poco importa el hecho de que de esta política no se benefician mucho los estratos pobres de las sociedades; al fin y a cabo, no son ellos quienes forman las élites político-culturales de un país, ni moldean la opinión pública nacional e internacional sobre las condiciones de vida y el desarrollo económico de un Estado.

Analizando el problema desde ésta perspectiva, la política del nacionalismo económico resulta no sólo comprensible, sino recomendable desde el punto de vista económico de los costos reales, ya que los llamados ingresos psicológicos disminuyen la carga financiera sin repercusiones sociales negativas. H. Johnnson dice literalmente: "Tal vez, la

${ }^{43}$ Ibidem, p. 20-4.

${ }^{44}$ H. Johnson, Economic Nationalism in Old and New States, 1968, Londres, p. 97-103. 


\section{JAN PATULA}

política nacionalista es el modo más barato y más eficiente para agrandar el ingreso real de los países en vías de desarrollo". "Se debe precisar que no cualquier nacionalismo económico - tampoco en toda ocasión y circunstancia - cumple el papel del acicate para el crecimiento y avance de un país. El autor observa que las prácticas nacionalistas pueden conducir a una hipertrofia económica; es decir, a su opuesto.

No queremos seguir enumerando tantas y tan variadas concepciones sobre el nacionalismo económico. Esta muestra evidencia una gran variedad de puntos de vista, con lo que se comprueba la conocida sentencia del lord Acton, quien ya en 1862, refiriéndose a Italia, constató: "El mismo espíritu sirvió a diferentes maestros, y contribuyó, primero, a la destrucción de antiguos Estados, luego a la expulsión de los franceses, y nuevamente, bajo la égida de Carlos Alberto, a una nueva revolución. Fue invocado en nombre de los más contradictorios principios de gobierno, y sirvió sucesivamente a todos los partidos, porque en él todo podía unificarse". ${ }^{46}$ Naturalmente, el autor del ensayo Nationality pensó en el nacionalismo político, cultural, lingüístico - lo que en su época era predominante- pero, mutatis mutandis, lo mismo se puede decir del nacionalismo económico.

Más allá de diferencias de enfoques, de simpatías o antipatías de autores en cuestión, de percepciones subjetivas del fenómeno del

44 nacionalismo económico, el cual tuvo mil y una caras en lo que se refiere a banderas, postulados, metas oficiales y ocultas, de condicionantes externos e internos, momentos coyunturales muy diversos, etc., podemos intentar enlistar ciertas prácticas o normas de conducta más recurrentes:

1. Un cuerpo legislativo, en algunos casos con inscripción formal en la Constitución de un país, sobre la estructura de propiedad (por ejemplo, la posesión nacionalizada del subsuelo y de todas las riquezas naturales de ciertas ramas o sectores de la industria, medios de transporte, bancos, etc.), así como del usufructo de ella (por ejemplo, las normas de concesión y/o limitación de este derecho a los extranjeros o a los miembros de una minoría étnica).

${ }^{45}$ Ibidem, p. 123.

${ }^{46}$ Cit. K.R. Minogue, op. cit., p. 210-11. 


\section{CONCEPCIONES DE NACIONALISMO ECONÓMICO}

2. Una política arancelaria y del comercio exterior dirigida a promover exportaciones y limitar las importaciones mediante una vasta gama de recursos de todo tipo.

3. Las prácticas encaminadas a promover la producción nacional, sea de la industria, sea de la agricultura o los servicios, mediante - por ejemplo- el subsidio directo, las descargas fiscales y de inversiones, la compra de los productos agrícolas, etc.

4. El trato desigual a los extranjeros o minorías étnicas en lo que respecta a la posesión, tráfico y transferencia de divisas dentro y fuera del país.

5. El trato inconstante a los extranjeros o minorías étnicas en cuanto a la participación en la dirección y administración de compañías estatales.

6. La regulación nacionalista sobre la mano de obra en el nivel de obreros no calificados, con los que ameriten calificaciones profesionales; limitación de la inmigración, desde la introducción de cuotas según nacionalidades, hasta la prohibición total.

7. El uso consciente y dirigido de la propaganda sobre los tópicos arriba mencionados.

8. La campaña de publicidad para promover y/o boicotear los productos nacionales y extranjeros.

Cada uno de estos puntos podría desmenuzarse para resaltar lo ilimitado de las prácticas del nacionalismo económico y ejemplificar en casos particulares de un país, un régimen o unas coyunturas concretas. Con este material se podrían escribir varios libros. 